Check for updates

Cite this: Phys. Chem. Chem. Phys., $2021,23,2622$

Received 10th December 2020, Accepted 14th January 2021

DOI: $10.1039 / \mathrm{d} 0 \mathrm{cp} 06381 \mathrm{a}$

rsc.li/pccp

\section{Anion effects on Li ion transference number and dynamic ion correlations in glyme-Li salt equimolar mixtures $\dagger$}

\author{
Keisuke Shigenobu, ${ }^{a}$ Masayuki Shibata, ${ }^{\mathrm{b}}$ Kaoru Dokko, (D) ac \\ Masayoshi Watanabe, (D) ${ }^{c}$ Kenta Fujii (D) ${ }^{* b}$ and Kazuhide Ueno (D)*ac
}

\begin{abstract}
To achieve single-ion conducting liquid electrolytes for the rapid charge and discharge of Li secondary batteries, improvement in the $\mathrm{Li}^{+}$transference number of the electrolytes is integral. Few studies have established a feasible design for achieving $\mathrm{Li}^{+}$transference numbers approaching unity in liquid electrolytes consisting of low-molecular-weight salts and solvents. Previously, we studied the effects of $\mathrm{Li}^{+}$-solvent interactions on the $\mathrm{Li}^{+}$transference number in glyme- and sulfolane-based molten $\mathrm{Li}$ salt solvates and clarified the relationship between this transference number and correlated ion motions. In this study, to deepen our insight into the design principles of single-ion conducting liquid electrolytes, we focused on the effects of $\mathrm{Li}^{+}$-anion interactions on $\mathrm{Li}$ ion transport in glyme- Li salt equimolar mixtures with different counter anions. Interestingly, the equimolar triglyme (G3)-lithium trifluoroacetate (Li[TFA]) mixture ([Li(G3)][TFA]) demonstrated a high $\mathrm{Li}^{+}$ transference number, estimated via the potentiostatic polarization method $\left(t_{L i}^{P P}=0.90\right)$. Dynamic ion correlation studies suggested that the high $t_{\mathrm{Li}}^{\mathrm{PP}}$ could be mainly ascribed to the strongly coupled $\mathrm{Li}^{+}$-anion motions in the electrolytes. Furthermore, high-energy $X$-ray total scattering measurements combined with all-atom molecular dynamics simulations showed that $\mathrm{Li}^{+}$ions and [TFA] anions aggregated into ionic clusters with a relatively long-range ion-ordered structure. Therefore, the collective motions of the $\mathrm{Li}$ ions and anions in the form of highly aggregated ion clusters, which likely diminish rather than enhance ionic conductivity, play a significant role in achieving high $t_{\mathrm{Li}}^{\mathrm{PP}}$ in liquid electrolytes. Based on the dynamic ion correlations, a potential design approach is discussed to accomplish single-ion conducting liquid electrolytes with high ionic conductivity.
\end{abstract}

\section{Introduction}

The feasibility of achieving rapid charge and discharge capabilities in $\mathrm{Li}$ secondary batteries has spurred significant interest in

\footnotetext{
${ }^{a}$ Department of Chemistry and Life Science, Yokohama National University, 79-5 Tokiwadai, Hodogaya-ku, Yokohama 240-8501, Japan. E-mail: uenokazuhide-rc@ynu.ac.jp; Fax: +81-45-339-3951; Tel: +81-45-339-3951

${ }^{b}$ Graduate School of Sciences and Technology for Innovation, Yamaguchi University, 2-16-1 Tokiwadai, Ube, Yamaguchi 755-8611, Japan E-mail: k-fujii@yamaguchi-u.ac.jp; Fax: +81-836-85-9212; Tel: +81-836-85-9212

${ }^{c}$ Advanced Chemical Energy Research Centre (ACERC), Institute of Advanced

Sciences, Yokohama National University, 79-5 Tokiwadai, Hodogaya-ku, Yokohama 240-8501, Japan

$\dagger$ Electronic supplementary information (ESI) available: Plots of the $\mathrm{Li}^{\prime} \mathrm{Li}^{+}$electrode potential against the natural logarithm of the Li salt concentration in the mixture of LiX in glyme (G3 or G4); the product of $t_{\mathrm{Li}}^{\mathrm{PP}}$ and $\sigma_{\text {ion }}$ versus ionicity; X-ray structure factors $S(q)$ and corresponding radial distribution functions in the form of $\left[r^{2}[G(r)-1]\right] \mathrm{s}$; snapshot of the coordination structure of $\left[\mathrm{Li}_{2}(\mathrm{G} 3)_{2}\right]^{2+} ; \mathrm{Li}^{+}-\mathrm{Li}^{+}$ pair correlation function $\left[g_{\mathrm{Li}-\mathrm{Li}}^{\mathrm{MD}}(r)\right.$ for $[\mathrm{Li}(\mathrm{G} 3)][\mathrm{TFSA}]$; numerical data for the composition of the systems and density values; force field parameters; the six experimentally obtained parameters for the calculation of the Onsager and normalized transport coefficients; $\mathrm{Li}-\mathrm{Li}$ distances obtained from the crystal structure of Li[TFA] and G4 mixture. See DOI: 10.1039/d0cp06381a
}

enhancing $\mathrm{Li}^{+}$ion transport properties, including the ionic conductivity and $\mathrm{Li}^{+}$transference number of liquid electrolytes. ${ }^{1-3}$ In general, the ionic conductivity of the electrolyte is believed to be the most important parameter for improving the rapid charge/ discharge ability, and many studies have focused on enhancing the ionic conductivity of electrolyte materials. Liquid electrolytes with a salt concentration of $\sim 1 \mathrm{~mol} \mathrm{dm}^{-3}$ are usually employed for battery applications because of their maximum conductivity in this concentration range. Over the past decade, however, highly concentrated electrolytes including molten Li salt solvates have captured significant attention owing to their unique electrochemical, physicochemical, and thermal properties, despite their low ionic conductivity. Li secondary batteries using concentrated liquid electrolytes have demonstrated improved rate capability, longterm cycling, and high coulombic efficiency. ${ }^{4-7}$ The unique cation transport decoupled from viscosity and the relatively high cationic transference number of the concentrated electrolytes have been considered as possible reasons for the improved rate capability. ${ }^{8-10}$

In the design of liquid electrolytes with high $\mathrm{Li}^{+}$transport properties, the enhancement of the $\mathrm{Li}^{+}$transference number remains challenging. Indeed, few studies have undertaken a 
profound analysis of the $\mathrm{Li}^{+}$transference number, although this parameter has often been used to discuss the rapid charge and discharge capability. ${ }^{11}$ The literature values of $\mathrm{Li}^{+}$transference numbers have been summarized and discussed for carbonatebased organic electrolyte solutions, ${ }^{12,13}$ and the anion dependence of the $\mathrm{Li}^{+}$transference number has been studied for organic ${ }^{14,15}$ and polymer electrolytes. ${ }^{16-19}$ To deepen our fundamental understanding of $\mathrm{Li}$ ion conduction along with the $\mathrm{Li}^{+}$transference number, we previously investigated solvent effects on the $\mathrm{Li}^{+}$ transference number for molten $\mathrm{Li}$ salt solvates of lithium bis(trifluoromethanesulfonyl)amide (Li[TFSA]) with glymes $\left(\mathrm{CH}_{3} \mathrm{O}\left(\mathrm{CH}_{2} \mathrm{CH}_{2} \mathrm{O}\right)_{n} \mathrm{CH}, \mathrm{Gn}\right)$ and sulfolane (SL) and their relationship with ion cross-correlations (cation-cation, anion-anion, and cation-anion) based on the Onsager reciprocal relations. ${ }^{20} \mathrm{We}$ found that the extremely low $\mathrm{Li}^{+}$transference number (0.028) of $[\mathrm{Li}(\mathrm{G} 4)][\mathrm{TFSA}]$, estimated via the potentiostatic polarization, was predominantly caused by the anti-correlated cation-cation motions of crown-ether-like, robust $[\mathrm{Li}(\mathrm{G} 4)]^{+}$complex cations, while the relatively high $\mathrm{Li}^{+}$transference number $(\sim 0.7)$ of SL-based molten Li salt solvates was ascribed to weaker anti-correlations of cationcation and cation-anion motions in a unique SL-bridged $\mathrm{Li}^{+}$ion coordination structure. Thus, these different ion-solvent interactions and ion correlations in the electrolytes are crucial determinants for the $\mathrm{Li}^{+}$transference number.

The interaction between $\mathrm{Li}^{+}$ions and counter anions is also a key factor governing the $\mathrm{Li}^{+}$ion coordination structure and $\mathrm{Li}^{+}$ transport properties. In a previous study, the effects of $\mathrm{Li}^{+}$-anion interactions on the stability of the complex cation and ionic transport properties of the glyme-Li salt equimolar mixtures with different Li salts ([Li(glyme) $] \mathrm{X})$ were systematically studied. ${ }^{21}$ Robust $[\mathrm{Li}(\text { glyme })]^{+}$complex cations were formed only with weakly coordinating, bulky anions (such as [TFSA]), while the glyme molecules remained uncoordinated to some extent in $[\mathrm{Li}($ glyme $)] \mathrm{X}$ with strongly Lewis basic anions. [Li(glyme)]X with dissociative perfluorinated sulfonylamide anions (such as [TFSA]) showed higher ionic conductivities and apparent dissociation degrees (or ionicities) than $[\mathrm{Li}($ glyme $)] \mathrm{X}$ with more Lewis basic anions.

Herein, we report the effects of $\mathrm{Li}^{+}$-anion interactions on the $\mathrm{Li}^{+}$ transference number of [Li(glyme)]X, for $\mathrm{X}$ ranging from weakly coordinating anions (such as [TFSA]) to moderately basic anions (such as trifluoromethanesulfonate ([TfO]), $\mathrm{BF}_{4}$, and $\mathrm{ClO}_{4}$ ) to strongly Lewis basic anions (such as $\mathrm{NO}_{3}$ and trifluoroacetate [TFA]). The anion dependence of the $\mathrm{Li}^{+}$ion transport mechanism is further discussed in the context of dynamic ion correlations based on Roling and Bedrov's concentrated solution theory. ${ }^{22}$ Finally, we conducted high-energy X-ray total scattering (HEXTS) experiments combined with all-atom molecular dynamics (MD) simulations to clarify the relationship between the dynamic ion correlations and solution structures in the equimolar glyme-Li salt mixtures.

\section{Experimental}

\subsection{Materials}

Purified triglyme (G3) and tetraglyme (G4) were kindly supplied by Nippon Nyukazai Co. (Japan). Lithium bis(trifluoromethanesulfonyl)amide
(Li[TFSA]) was kindly provided by Solvay Japan. Battery-grade Li salts-lithium bis(fluorosulfonyl)amide (Li[FSA]), lithium bis(pentafluoroethanesulfonyl)amide (Li[BETA]), lithium trifluoromethanesulfonate ( $\mathrm{Li}[\mathrm{TfO}]), \mathrm{LiBF}_{4}$, and $\mathrm{LiClO}_{4}$-were purchased from Kishida Chemical Co. (Japan). The other Li salts-lithium bis(nonafluorobutanesulfonyl)amide (Li[NFSA]), lithium trifluoroacetate $(\mathrm{Li}[\mathrm{TFA}])$ and $\mathrm{LiNO}_{3}$-were obtained from Mitsubishi Materials Electronic Chemicals Co. (Japan), Alfa Aesar and FUJIFILM Wako Pure Chemical Co. (Japan), respectively. All glyme-Li salt mixtures were prepared in an inert argon-filled glove box $\left(\left[\mathrm{H}_{2} \mathrm{O}\right]\right.$ $\left.<1 \mathrm{ppm} ;\left[\mathrm{O}_{2}\right]<1 \mathrm{ppm}\right)$.

\subsection{Measurements}

The experiments to determine two different $\mathrm{Li}^{+}$transference numbers $\left(t_{\mathrm{Li}}^{\mathrm{NMR}}\right.$ and $\left.t_{\mathrm{Li}}^{\mathrm{PP}}\right)$, the salt diffusion coefficients, and electrode potentials of $\mathrm{Li} / \mathrm{Li}^{+}$conducted in this study were performed according to our previous report. ${ }^{20}$ In brief, for the $\mathrm{Li}^{+}$transference number determined by the potentiostatic polarization method $\left(t_{\mathrm{Li}}^{\mathrm{PP}}\right)$, experiments were performed using a Li symmetric cell. A porous glass filter paper (Advantec, GA55, $17 \mathrm{~mm}$ in diameter) or two pieces of microporous propylene membrane separator (Celgard, Celgard3501, $17 \mathrm{~mm}$ in diameter) soaked in the liquid electrolyte were inserted into two $\mathrm{Li}$ foil electrodes (Honjo Metal, $16 \mathrm{~mm}$ in diameter) in a 2032 coin-type cell. Impedance spectra were measured in the frequency range of $100 \mathrm{mHz}-1 \mathrm{MHz}$ with a voltage amplitude of $10 \mathrm{mV}$ using a potentiostat (Solartron Analytical, ModuLab XM ECS). The salt diffusion coefficients $\left(D_{\text {salt }}\right)$ were determined using the same Li symmetric coin cell according to the literature. ${ }^{23}$ The cell was polarized at $10 \mathrm{mV}$ in potentiostatic mode and the relaxation of the cell potential was recorded after the applied potential was removed. $D_{\text {salt }}$ was determined by fitting the potential relaxation with a single exponential decay function. The electrode potentials of $\mathrm{Li} / \mathrm{Li}^{+}(\Delta \varphi)$ were measured via a reference electrode $\left(\mathrm{Li} / \mathrm{Li}^{+}\right.$ in $\left.1 \mathrm{~mol} \mathrm{dm}^{-3} \mathrm{Li}[\mathrm{TFSA}] / \mathrm{G} 3\right)$ using a multi-compartment concentration cell (Fig. S1, ESI $\dagger$ ). ${ }^{24}$ Vycor glass was used for the junction between the reference electrolyte and the sample electrolytes. The potential was recorded using a potentiostat. A slope $\mathrm{d} \Delta \varphi$ / $\mathrm{d} \ln (c)$ at a given concentration was obtained from the slope of the concentration dependence of the concentration cell potential. ${ }^{22}$ All the above measurements were performed at $30{ }^{\circ} \mathrm{C}$ unless otherwise noted.

High-energy X-ray total scattering measurements for the electrolytes were conducted at ambient temperature using an X-ray diffraction apparatus ${ }^{25}$ (BL04B2 beamline at SPring-8, JASRI, Japan). Monochrome $61.6 \mathrm{keV}$ X-rays were obtained using a $\mathrm{Si}(220)$ monochromator. The observed X-ray scattering intensities were corrected for adsorption, polarization, and incoherent scattering to obtain coherent scattering intensities, $I_{\text {coh }}(q) .^{26-28}$

The X-ray structure factor $S^{\mathrm{HEXTS}}(q)$ per stoichiometric volume was expressed as follows:

$$
S^{\operatorname{HEXTS}}(q)=\frac{\frac{I_{\text {coh }}(q)}{N}-\sum n_{i} f_{i}(q)^{2}}{\left\{\sum n_{i} f_{i}(q)\right\}^{2}}+1
$$


where $n_{i}$ and $f_{i}(q)$ correspond to the number and atomic scattering factor of atom $i$, respectively. The X-ray radial distribution function $G^{\text {HEXTS }}(q)$ was calculated from the inverse Fourier transform of $S^{\operatorname{HEXTS}}(q):$

$$
G^{\exp }(r)-1=\frac{1}{2 \pi^{2} r \rho_{0}} \int_{0}^{q_{\max }} q\left[S^{\exp }(q)-1\right] \sin (q r) \frac{\sin \left(q \pi / q_{\max }\right)}{q \pi / q_{\max }} \mathrm{d} q
$$

where $\rho_{0}$ corresponds to the number density of atoms and $q_{\max }$ represents the maximum value of $q\left(=25 \AA^{-1}\right.$ in this study).

\subsection{MD simulations}

The MD simulations were performed with the GROMACS 2016.5 program under the NTP ensemble condition controlled by the Nosé-Hoover thermostat ${ }^{29,30}$ (at $298 \mathrm{~K}$ and $1 \mathrm{~atm}$ ). To ensure the random starting configuration, firstly, we mixed $\mathrm{Li}^{+}$ [TFA $]^{-}$and G3 molecules at high temperature and pressure (1000 K and $1000 \mathrm{~atm}$, respectively) for $1 \mathrm{~ns}$. The composition (i.e., the number of $\mathrm{Li}[\mathrm{TFSA}]$ and $\mathrm{Li}[\mathrm{TFA}]$ ion pairs, respectively, and G3 molecules) in a cubic cell was as follows: Li[TFSA]/G3 = 790/790 and $\mathrm{Li}[\mathrm{TFA}] / \mathrm{G} 3=790 / 790$. The resulting box size and density at the equilibrium state are listed in Table S1 (ESI $\dagger$ ). The total simulation time was set as $\mathbf{1 5 . 0} \mathrm{ns}$ for both systems. The X-ray weighted structure factors $S^{\mathrm{MD}}(q)$ and radial distribution functions $G^{\mathrm{MD}}(q)$ were obtained by analyzing the data collected at $0.1 \mathrm{ps}$ intervals during the last 500 ps. CLaP and OPLS-AA force fields, including intermolecular Lennard-Jones (LJ) and coulombic interactions and intramolecular interactions with (1) bond stretching, (2) angle bending, and (3) torsion of dihedral angles, were used for $[\mathrm{TFSA}]]^{31}[\mathrm{TFA}]^{32-34}$ and G3. ${ }^{32,33,35}$ The LJ parameter for $\mathrm{Li}$ ions (see the $\mathrm{Li}$ salt/ carbonate solvent system $\left.{ }^{36}\right)$ was used. The partial charges $\left(q^{+}\right.$ and $q^{-}$) for TFA molecules (Fig. S2, ESI $\dagger$ ) were obtained from quantum chemical calculations (ChelpG method ${ }^{37}$ ); the resulting values are listed in Table S2 (ESI $\dagger$ ). Those for TFSA and G3 were similar to the values reported in a previous work. ${ }^{38}$

The $S^{\mathrm{MD}}(q)$ functions were calculated using the trajectories from the MD simulations as follows:

$$
\begin{aligned}
& S^{\mathrm{MD}}(q)= \\
& \left\{\begin{array}{l}
\frac{\sum_{i} \sum_{j}\left\{\frac{n_{i}\left(n_{j}-1\right) f_{i}(q) f_{j}(q)}{N(N-1)}\right\}}{\left\{\sum_{k}\left(\frac{n_{k} f_{k}(q)}{N}\right)\right\}^{2}} \int_{0}^{r} 4 \pi r^{2} \rho_{0}\left(g_{i j}^{\mathrm{MD}}(r)-1\right) \frac{\sin q r}{q r} \mathrm{~d} r+1(i=j) \\
\frac{\sum_{i} \sum_{j}\left\{\frac{2 n_{i} n_{j} f_{i}(q) f_{j}(q)}{N^{2}}\right\}^{r}}{\left\{\sum_{k}\left(\frac{n_{k} f_{k}(q)}{N}\right)\right\}^{2}} \int_{0}^{r} 4 \pi r^{2} \rho_{0}\left(g_{i j}^{\mathrm{MD}}(r)-1\right) \frac{\sin q r}{q r} \mathrm{~d} r+1(i \neq j)
\end{array}\right.
\end{aligned}
$$

where $N$ is the total number of atoms in the simulation box defined by $N=\sum_{k} n_{k}$, and $g_{i j}^{\mathrm{MD}}(r)$ is the atom-atom pair correlation function between atoms $i$ and $j$. The $G^{\mathrm{MD}}(q)$ functions were calculated from the corresponding $S^{\mathrm{MD}}(q) \mathrm{s}$, conducting a similar procedure to that of HEXTS.

\section{Results and discussion}

\section{1 $\mathrm{Li}^{+}$transference number under anion-blocking condition}

In our previous work, $\mathrm{Li}^{+}$transference numbers derived from the pulsed filed gradient (PFG)-NMR method $\left(t_{\mathrm{Li}}^{\mathrm{NMR}}\right)$ and potentiostatic polarization method $\left(t_{\mathrm{Li}}^{\mathrm{PP}}\right)$ were determined for Li-ion conducting electrolytes. ${ }^{21,39,40}$ The PFG-NMR method is based on the NernstEinstein equation: $t_{\mathrm{Li}}^{\mathrm{NMR}}=D_{\mathrm{Li}} /\left(D_{\mathrm{Li}}+D_{\text {anion }}\right)$, where $D_{\mathrm{Li}}$ and $D_{\text {anion }}$ are the self-diffusion coefficients of $\mathrm{Li}^{+}$ions and anions, respectively, and the ions are assumed to be completely dissociated and move independently as ideal dilute electrolyte solutions. Hence, for highly concentrated electrolytes, $t_{\mathrm{Li}}^{\mathrm{NMR}}$ would not reflect a realistic transference number because of their dynamic ion correlations.

The $\mathrm{Li}^{+}$transference number based on the potentiostatic polarization combined with electrochemical impedance spectroscopy ${ }^{41,42}\left(t_{\mathrm{Li}}^{\mathrm{PP}}\right)$ is defined as follows:

$$
t_{\mathrm{Li}}^{\mathrm{PP}}=\frac{I_{\mathrm{SS}}\left(V_{\mathrm{DC}}-I_{\mathrm{Ohm}} R_{\mathrm{i}, 0}\right)}{I_{\mathrm{Ohm}}\left(V_{\mathrm{DC}}-I_{\mathrm{SS}} R_{\mathrm{i}, \mathrm{SS}}\right)}
$$

where $V_{\mathrm{DC}}$ is a constant applied voltage, $I_{\mathrm{Ohm}}$ and $I_{\mathrm{SS}}$ are the initial and steady-state currents, and $R_{\mathrm{i}, 0}$ and $R_{\mathrm{i}, \mathrm{SS}}$ are the initial and steady-state interfacial resistance values, respectively. The initial current is calculated using Ohm's law, $I_{\mathrm{Ohm}}=V_{\mathrm{DC}} /\left(R_{\mathrm{bulk}}+\right.$ $\left.R_{\mathrm{i}, 0}\right)$, because the "measured" initial current data point $\left(I_{0}\right)$ strongly depends on the sampling time, which results in the inaccurate determination of $t_{\mathrm{Li}}^{\mathrm{PP}}$ in some cases. Similar to $t_{\mathrm{Li}}^{\mathrm{NMR}}$, $t_{\mathrm{Li}}^{\mathrm{PP}}$ represents the precise $\mathrm{Li}^{+}$transference number only for ideal dilute electrolyte solutions. According to Balsara et al., ${ }^{43}$ $t_{\mathrm{Li}}^{\mathrm{PP}}$ simply shows the "current fraction" in non-ideal electrolytes; however, $t_{\mathrm{Li}}^{\mathrm{PP}}$ is convenient for assessing $\mathrm{Li}^{+}$transport properties because the value includes migration and diffusion effects, which would also be observed in lithium ion batteries (under anion-blocking conditions).

Fig. 1(a) shows the $t_{\mathrm{Li}}^{\mathrm{PP}}$ of the glyme-Li salt equimolar mixtures plotted as a function of ionicity. Ionicity, defined as the molar conductivity ratio $\left(\Lambda / \Lambda_{\mathrm{NE}}\right)$, expresses the extent to which the self-diffusion of ionic species contributes to the actual ionic conduction and is relevant to the apparent degree of dissociation or dynamic ion correlations in electrolyte solutions. $^{39,44-48} \Lambda$ is the experimental molar conductivity and $\Lambda_{\mathrm{NE}}$ is calculated from self-diffusion coefficients using the Nernst-Einstein equation, $\Lambda_{\mathrm{NE}}=F^{2}\left(D_{\mathrm{Li}}+D_{\text {anion }}\right) / R T$, where $F$ is the Faraday constant, $R$ is the gas constant, and $T$ is the absolute temperature. As noted in previous papers, ${ }^{21,49}$ the strength order of Lewis basicity for the selected ions is [TFSA] $<\mathrm{ClO}_{4}<\mathrm{BF}_{4}<[\mathrm{TfO}]<\mathrm{NO}_{3}<$ [TFA], whereas their order of ionicity in $[\mathrm{Li}($ glyme $)] \mathrm{X}$ displays the exact opposite trend.

Interestingly, a good linear relationship is observed between $t_{\mathrm{Li}}^{\mathrm{PP}}$ and ionicity (Fig. 1(a)). [Li(glyme)]X with weakly coordinating anions such as the bis(perfluorosulfonyl)amides ([FSA], [TFSA], [BETA], [NFSA]) and $\mathrm{ClO}_{4}$ show significantly low $t_{\mathrm{Li}}^{\mathrm{PP}}$ values of less 
(a)

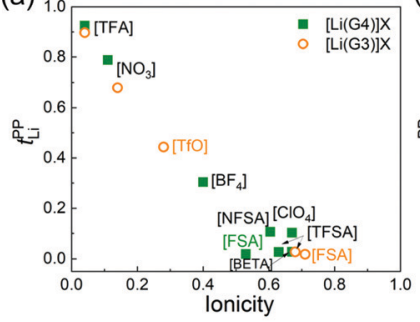

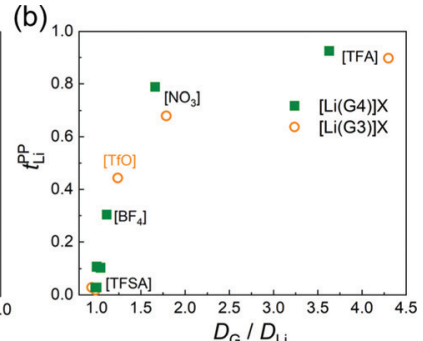

$D_{\mathrm{G}} / D_{\mathrm{Li}}$

Fig. 1 Relationships between (a) $t_{\mathrm{Li}}^{\mathrm{PP}}$ and ionicity, and (b) $t_{\mathrm{Li}}^{\mathrm{PP}}$ and $D_{\mathrm{G}} / D_{\mathrm{Li}}$ for [Li(glyme)]X. lonicity and $D_{\mathrm{G}} / D_{\mathrm{Li}}$ values were obtained from ref. 21 .

than 0.1. The value of $t_{\mathrm{Li}}^{\mathrm{PP}}$ increases with decreasing ionicity (i.e., increasing Lewis basicity of the anions). The highest value of $t_{\mathrm{Li}}^{\mathrm{PP}}$ is 0.93 for $[\mathrm{Li}(\mathrm{G} 4)][\mathrm{TFA}]$, with the lowest ionicity of 0.04 , whereas the lowest $t_{\mathrm{Li}}^{\mathrm{Pp}}$ value of 0.016 is observed for $[\mathrm{Li}(\mathrm{G} 3)][\mathrm{FSA}]$, with the highest ionicity of 0.71 . In Fig. $1(\mathrm{~b}), \mathrm{t}_{\mathrm{Li}}^{\mathrm{PP}}$ values are plotted against the ratios of the self-diffusion coefficients of the glyme and $\mathrm{Li}^{+}$ions $\left(D_{\mathrm{G}} / D_{\mathrm{Li}}\right)$. Here, $D_{\mathrm{G}} / D_{\mathrm{Li}}$ reflects the stability of [Li(glyme) $]^{+}$complex ions in the equimolar glyme-Li salt mixtures. ${ }^{21} D_{\mathrm{G}} / D_{\mathrm{Li}} \approx 1$ (for [Li(glyme)]X with weakly coordinating anions, such as [Li(G3)][TFSA]) indicates the coupled diffusion of the glyme and $\mathrm{Li}^{+}$ions in the form of [Li(glyme) $]^{+}$complex ions. In contrast, if $D_{\mathrm{G}} /$ $D_{\mathrm{Li}}>1$ (for [Li(glyme)]X with strongly Lewis basic anions, such as [Li(G3)][TFA]], the complex ions are considered to be short-lived or unstable, and the glymes remain uncoordinated to some extent in the equimolar glyme-Li salt mixtures.

The anion-dependent stability of $[\mathrm{Li}(\mathrm{glyme})]^{+}$complex ions was also evaluated in light of the $\mathrm{Li}^{+}$-glyme residence time using MD simulations. ${ }^{50}$ The residence time of the $\mathrm{Li}^{+}$-glyme complex was much shorter than that of the $\mathrm{Li}^{+}$-anion pair for the glyme-Li salt mixtures with strongly Lewis basic anions (such as [TFA]). As a consequence of strong $\mathrm{Li}^{+}$-anion interactions, uncoordinated glymes and $\mathrm{Li}^{+}$-anion pairs mainly comprise the glyme-Li salt mixtures with Lewis basic anions. Therefore, the presence of uncoordinated (or highly exchangeable) glymes and/or $\mathrm{Li}^{+}$-anion pairs is suggested to be responsible for the high $t_{\mathrm{Li}}^{\mathrm{PP}}$ values of $[\mathrm{Li}(\mathrm{glyme})] \mathrm{X}$ with strongly Lewis basic anions. MD simulations by Bedrov et al. demonstrated that the enhancement of the $\mathrm{Li}^{+}$transference number under anion-blocking conditions is attributable to the reduction of $\mathrm{Li}^{+}$-solvent residence time by shortening the chain length of the glymes. ${ }^{22}$ In this regard, our results shown in Fig. 1(b) are in good agreement with their notion: the presence of free (or highly exchangeable) glyme, which is accompanied by strong $\mathrm{Li}^{+}$-anion interactions in the present system, results in high $t_{\mathrm{Li}}^{\mathrm{pP}}$ values.

The relationship between $t_{\mathrm{Li}}^{\mathrm{PP}}$ and the ionic conductivity of [Li(glyme)]X is illustrated in Fig. 2. The lowest ionic conductivity of $0.083 \mathrm{mS} \mathrm{cm}^{-1}$ is observed for [Li(G4)][TFA], with the highest $t_{\mathrm{Li}}^{\mathrm{PP}}$ value of 0.93 , whereas the highest ionic conductivity of $1.7 \mathrm{mS} \mathrm{cm}{ }^{-1}$ is achieved for [Li(G3)][FSA], with the lowest $t_{\mathrm{Li}}^{\mathrm{PP}}$ value of 0.016 . The figure clearly indicates that more Lewis basic anions contribute to the enhancement of $t_{\mathrm{Li}}^{\mathrm{PP}}$, while decreasing the ionic conductivity. Balsara et al. confirmed a similar "tradeoff" between the $\mathrm{Li}^{+}$transference number and ionic conductivity

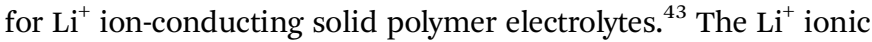

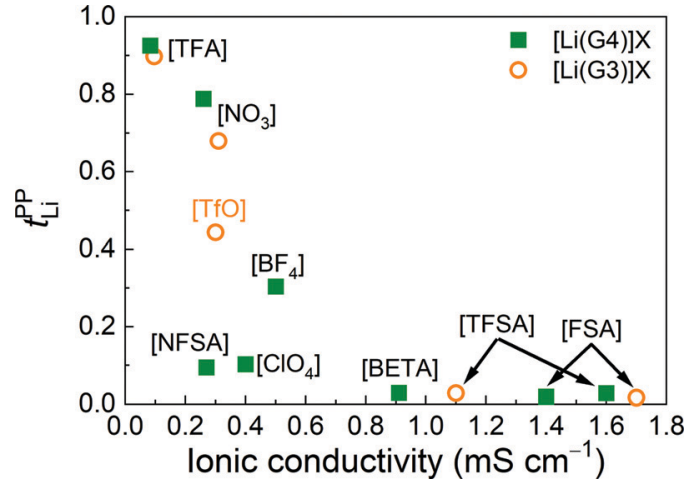

Fig. 2 Plots of $t_{\mathrm{Li}}^{\mathrm{PP}}$ versus ionic conductivity for [Li(glyme)]X.

conductivity characterized by the product of $t_{\mathrm{Li}}^{\mathrm{PP}}$ and the conductivity is larger for [Li(glyme)]X with $\mathrm{NO}_{3}$, [TfO] and $\mathrm{BF}_{4}$ anions than [Li(glyme)]X with strongly Lewis basic [TFA] and weakly coordinating anions such as [FSA] (see Fig. S3, ESI†). Thus, higher $\mathrm{Li}^{+}$transport properties can be achieved with the moderately basic anions. In the following sections, we investigate the causes underlying the enhancement of $t_{\mathrm{Li}}^{\mathrm{PP}}$ for strongly Lewis basic anions and the inverse relationship between $t_{\mathrm{Li}}^{\mathrm{PP}}$ and ionic conductivity from the viewpoint of dynamic ion correlations and liquid structures.

\subsection{Dynamic ion correlations}

For aqueous electrolyte solutions, dynamic ion correlations were systematically evaluated based on the velocity crosscorrelation functions by Woolf and Harris. ${ }^{51,52}$ For solid polymer electrolytes, recently, Balsara and Newman investigated the correlations by introducing the Stefan-Maxwell diffusion coefficients. ${ }^{43,53,54}$ Regarding non-aqueous liquid electrolyte solutions, dynamic ion correlations were derived from the Onsager transport coefficients and were first applied for the glyme molten Li salt solvates of Li[TFSA] by Roling and Bedrov et al. ${ }^{22,55,56}$ In our previous work, we discussed transport behavior in glyme- and SL-based molten Li salt solvates by introducing experimentally determined transport coefficients. The Onsager transport coefficients can describe the ionic conductivity $\sigma_{\text {ion }}$ as follows:

$$
\sigma_{\text {ion }}=\sigma_{++}+\sigma_{--}-2 \sigma_{+-}
$$

Here, $\sigma_{++}$and $\sigma_{--}$consist of self-terms and distinct terms, respectively, and the ionic conductivity $\sigma_{\text {ion }}$ is expressed as

$$
\sigma_{\text {ion }}=\sigma_{+}^{\text {self }}+\sigma_{++}^{\text {distinct }}+\sigma_{-}^{\text {self }}+\sigma_{--}^{\text {distinct }}-2 \sigma_{+-} .
$$

All the Onsager transport coefficients $\left(\sigma_{++}, \sigma_{--}\right.$, and $\left.\sigma_{+-}\right)$can be calculated from four experimental quantities $-\sigma_{\text {ion }}, t_{\mathrm{Li}}^{\mathrm{PP}}, D_{\text {salt }}$, and $\mathrm{d} \Delta \varphi / \mathrm{d} \ln (c)$; these data are shown in Table S3 (ESI $\dagger$ ). The detailed procedure for estimating the transport coefficients was described in a previous paper. ${ }^{20}$ The dynamic cross-correlations of the ions (cation-cation, anion-anion, cation-anion) are indicated by the signs of $\sigma_{++}^{\text {distinct }}, \sigma_{--}^{\text {distinct }}$, and $\sigma_{+-}$, respectively. The sign of the cross-correlation is positive in the case of correlated ion motions, while the sign is negative for anti-correlated 
motions. In addition, a value of zero for these correlations indicates non-correlated interionic dynamics, as predicted in ideal electrolyte solutions.

To clarify the effects of the interionic dynamics on the anionic dependency of $t_{\mathrm{Li}}^{\mathrm{PP}}$ and the trade-off between $t_{\mathrm{Li}}^{\mathrm{PP}}$ and ionic conductivity, the ion dynamics for the extraordinary case of $[\mathrm{Li}(\mathrm{G} 3)][\mathrm{TFA}]$ was compared with those of another extreme case, $[\mathrm{Li}(\mathrm{G} 3)]\left[\right.$ TFSA] , reported in our prior study. ${ }^{20}$ As discussed in the previous section, both glyme-Li salt mixtures show exactly opposite properties: [Li(G3)][TFA] shows high $t_{\mathrm{Li}}^{\mathrm{PP}}$ but poor ionic conductivity, and [Li(G3)][TFSA] displays high ionic conductivity but very low $t_{\mathrm{Li}}^{\mathrm{PP}}$.

The normalized Onsager transport coefficients $\left(\sigma_{+}^{\text {self }}, \sigma_{-}^{\text {self }}\right.$, $\sigma_{++}^{\text {distinct }}, \sigma_{--}^{\text {distinct }}$, and $\sigma_{+-}$divided by $\left.\sigma_{\text {ion }}\right)$ of [Li(G3)][TFA] are shown in Fig. 3(a), and the numerical data are listed in Table S4 $(\mathrm{ESI} \dagger)$. Interestingly, all five coefficients $\left(\sigma_{+}^{\text {self }} / \sigma_{\text {ion }}, \sigma_{-}^{\text {self }} / \sigma_{\text {ion }}\right.$, $\sigma_{++}^{\text {distinct }} / \sigma_{\text {ion }}, \quad \sigma_{--}^{\text {distinct }} / \sigma_{\text {ion }}$, and $\left.\sigma_{+-} / \sigma_{\text {ion }}\right)$ are positive for [Li(G3)][TFA]. This is distinctly different from the results for the previously studied $[\mathrm{Li}(\mathrm{G} 3)][\mathrm{TFSA}]$, for which $\sigma_{++}^{\text {distinct }} / \sigma_{\text {ion }}$, $\sigma_{--}^{\text {distinct }} / \sigma_{\text {ion }}$, and $\sigma_{+-} / \sigma_{\text {ion }}$ were all negative. ${ }^{20}$ Fig. $3(\mathrm{~b})$ depicts the $\sigma_{+-} / \sigma_{\text {ion }}$ values for $[\mathrm{Li}(\mathrm{G} 3)][\mathrm{TFSA}],[\mathrm{Li}(\mathrm{G} 4)]\left[\mathrm{BF}_{4}\right]$, and $[\mathrm{Li}(\mathrm{G} 3)][\mathrm{TfO}] . \quad \sigma_{+-} / \sigma_{\text {ion }}$ shifts from a negative value for $[\mathrm{Li}(\mathrm{G} 3)][\mathrm{TFSA}]$ to moderately positive values for $[\mathrm{Li}(\mathrm{G} 4)]\left[\mathrm{BF}_{4}\right]$ and $[\mathrm{Li}(\mathrm{G} 3)][\mathrm{TfO}]$, and a largely positive value for $[\mathrm{Li}(\mathrm{G} 3)][\mathrm{TFA}]$ (Fig. 3(a)), confirming that the $\sigma_{+-} / \sigma_{\text {ion }}$ value is reflective of the $\mathrm{Li}^{+}$-anion interactions in [Li(glyme) $] \mathrm{X}$.

The correlated motions of the ion species with the same sign contribute to the enhancement of the ionic conductivity; however, the correlated motions of the cation-anion negatively affect the ionic conductivity. Thus, the correlated cation-anion motions almost offset the positive contribution from $\sigma_{+}^{\text {self }}, \sigma_{-}^{\text {self }}, \sigma_{++}^{\text {distinct }}$, and $\sigma_{-}^{\text {distinct }}$ to the ionic conductivity; therefore, [Li(G3)][TFA] exhibits very low ionic conductivity among the glyme-Li salt mixtures studied here.

In addition, the normalized values of the five Onsager transport coefficients for [Li(G3)][TFA] (Fig. 3(a)) are nearly hundreds of times larger than those of [Li(G3)][TFSA] simply because of its low ionic conductivity. The calculation of the five transport coefficients is affected by the self-diffusion coefficients determined for $\mathrm{Li}^{+}$and the anions. The larger values of the normalized coefficients suggest that the measured selfdiffusion coefficients of the ions in [Li(G3)][TFA] contribute little to the actual ionic conductivity $\left(\sigma_{\text {ion }}\right)$. The largely positive

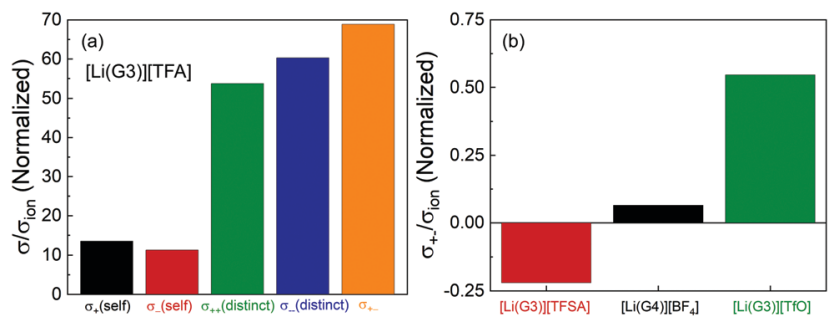

Fig. 3 (a) All Onsager transport coefficients $\left(\sigma_{+}^{\text {self }}, \sigma_{-}^{\text {self }}, \sigma_{++}^{\text {distinct }}, \sigma_{--}^{\text {distinct }}\right.$ and $\sigma_{+-}$: left to right) normalized by $\sigma_{\text {ion }}$ of [Li(G3)][TFA], and (b) differences in $\sigma_{+-}$(cross-correlation of cation-anion) of several G3- or G4-based glyme-Li salt equimolar mixtures. values of $\sigma_{++}^{\text {distinct }} / \sigma_{\text {ion }}, \sigma_{--}^{\text {distinct }} / \sigma_{\text {ion }}$, and $\sigma_{+-} / \sigma_{\text {ion }}$ for [Li(G3)][TFA] (Fig. 3(a)) suggest that all of the ions tend to move preferentially in the same direction. These results raise the possibility that $\mathrm{Li}^{+}$ ions and [TFA] anions form ionic aggregates or ion clusters of $\left[\mathrm{Li}_{x}^{+}\left([\mathrm{TFA}]^{-}\right)_{y}\right]^{(x-y)}$ as well as neutral ion pairs of $\mathrm{Li}-[\mathrm{TFA}]$.

\subsection{Liquid structures}

The solution structures of [Li(G3)][TFA] and [Li(G3)][TFSA] were investigated HEXTS and all-atom MD simulations. Fig. S4 $(\mathrm{ESI} \dagger)$ shows the X-ray structure factors, $S(q)$ s, obtained from HEXTS and MD simulations within the $q$ range of $0-20 \AA$. In addition, Fig. S5 (ESI $\dagger$ ) illustrates the corresponding X-ray radial distribution functions, $r^{2}\{G(r)-1\}$, in the $r$ range of 0-25 A. In both cases, the $S(q)$ s and corresponding $\left[r^{2}\{G(r)-1\}\right]$ s obtained from the MD simulations reproduce the HEXTS profiles accurately. Therefore, we can further consider the coordination structures and intramolecular/intermolecular interactions through analysis of MD simulations. It is possible to transform the $\left[r^{2}\{G(r)-1\}\right] \mathrm{s}$ into atom-atom pair correlation functions for each component. The correlation functions of the $\mathrm{Li}^{+}-\mathrm{Li}^{+}$and $\mathrm{Li}^{+}$-anions are depicted in Fig. 4.

Fig. 4(a) shows the atom-atom pair correlation function $(g)$ between the $\mathrm{Li}$ ions of [Li(G3)][TFSA] and [Li(G3)][TFA]. Regarding [Li(G3)][TFSA], two sharp peaks appear at 3.0 and $9.2 \AA$, corresponding to the $\left[g_{\mathrm{Li}-\mathrm{Li}}^{\mathrm{MD}}(r)\right]$ for $\mathrm{Li}^{+}$-glyme complexes. The first peak can be assigned to the $\mathrm{Li}^{+}-\mathrm{Li}^{+}$correlation, which is attributable to the two Li ions coordinated with same G3 molecule, suggesting the formation of dimers such as $\left[\mathrm{Li}_{2}(\mathrm{G} 3)_{2}\right]^{2+}$ in this electrolyte (Fig. S6, ESI $\dagger$ ); however, because the cumulative coordination number $(N(r))$ is lower than 0.15 (see Fig. S7, ESI $\dagger$ ), the existence probability of this structure is low. The second peak (9.2 $\mathrm{A}$ ) can be attributed to a correlation between $[\mathrm{Li}(\mathrm{G} 3)]^{+}$complexes. This result is strongly supported by the previous study for $[\mathrm{Li}(\mathrm{G} 4)][\mathrm{TFSA}] .^{35}$ The potential mean force (PMF) for the $\mathrm{Li}^{+}-\mathrm{Li}^{+}$ pair correlation $\left(\mathrm{PMF}=-R T \ln g_{\mathrm{Li}-\mathrm{Li}}^{\mathrm{MD}}(r)\right)$ of $[\mathrm{Li}(\mathrm{G} 4)][\mathrm{TFSA}]$ has a minimum value at $9.5 \AA$, suggesting that stable $[\mathrm{Li}(\mathrm{G} 4)]^{+}$complex cations predominantly exist by maintaining the distance between the other complex cations. ${ }^{35}$

In contrast, multiple sharp peaks appear in the correlation function for [Li(G3)][TFA]. These peaks start to emerge at $3.8 \AA$ and continue until $12.8 \AA$ with nearly regular intervals between peaks. This strongly suggests that the $\mathrm{Li}^{+}-\mathrm{Li}^{+}$correlation in
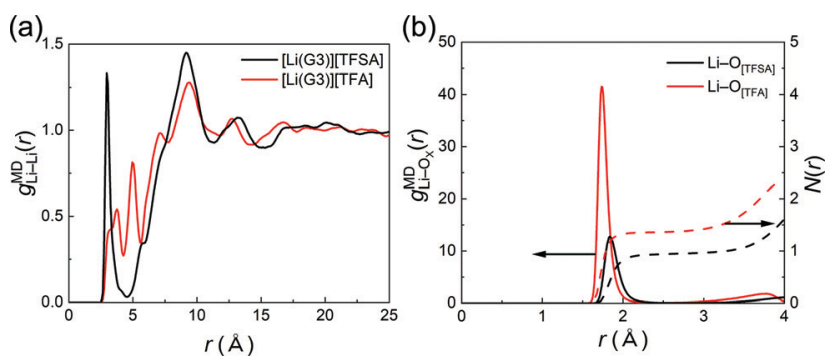

Fig. 4 Atom-atom pair correlation functions $\left[g_{\text {atom-atom }}^{\mathrm{MD}}(r)\right] \mathrm{s}$ between (a) $\mathrm{Li}$-ions and (b) for the $\mathrm{O}$ atoms of anions around $\mathrm{Li}$ ions and integrated profiles (cumulative coordination number: $N(r)$ ) for [Li(G3)][TFSA] and [Li(G3)][TFA]. 


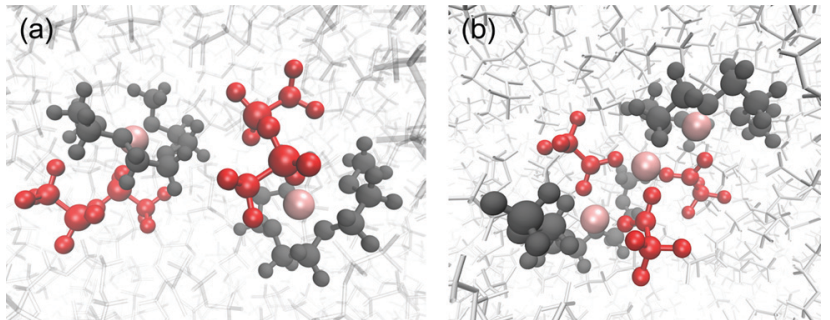

Fig. 5 Snapshots of the coordination structures found in (a) [Li(G3)][TFSA] and (b) [Li(G3)][TFA] obtained from MD simulations. Pink: $\mathrm{Li}^{+}$, red: anions and dark grey: G3.

[Li(G3)][TFA] can be ascribed not only to $\mathrm{Li}^{+}$-solvent (G3) interactions but also to $\mathrm{Li}^{+}$-anion interactions, and a continuous $\mathrm{Li}^{+}-$ ordered structure is formed as a polynuclear complex over a relatively long distance. Similar long-range ion-ordering was also observed in a highly concentrated electrolyte of Li[TFSA] in $N, N$ dimethylformamide. ${ }^{57}$ Fig. 4(b) shows the $\mathrm{Li}^{+}$-anion pair correlations and the integrated profile (cumulative coordination number: $N(r)$ ) for each electrolyte, where the distance for the correlations of $\mathrm{Li}^{+}$-[TFA] anions is shorter than that of $\mathrm{Li}^{+}$-[TFSA]. In addition, the intensity of the peak for the $\mathrm{Li}^{+}-[\mathrm{TFA}]$ anion correlation is four times larger and the shape of the peak is much sharper. Moreover, the cumulative number of $\mathrm{Li}^{+}$-[TFA] anions is much higher than that of $\mathrm{Li}^{+}-[\mathrm{TFSA}]$. These findings are consistent with the solution structure presumed from the dynamic ion correlations of [Li(G3)][TFA] investigated in the previous section: [TFA] anions strongly interact with $\mathrm{Li}^{+}$, and the aggregating structure is dominant in [Li(G3)][TFA].

Snapshots of the coordination structures of [Li(G3)][TFSA] and $[\mathrm{Li}(\mathrm{G} 3)][\mathrm{TFA}]$ are presented in Fig. 5. As shown in Fig. 5(a), the four $\mathrm{O}$ atoms of $\mathrm{G} 3$ coordinate to one $\mathrm{Li}$ ion to form a stable $[\mathrm{Li}(\mathrm{G} 3)]^{+}$complex cation along with one [TFSA] anion to compensate for the positive charge in [Li(G3)][TFSA]. This structure is in good agreement with those reported in previous experimental and computational works. ${ }^{50,58,59}$

In contrast, based on the results of the correlation function $(g(r))$, a continuously ordered $\mathrm{Li}^{+}$structure is formed in [Li(G3)][TFA] by coordinating both G3 and [TFA] anions (Fig. 5(b)). A similar coordination structure was confirmed in the solid crystal structure of a Li[TFA] and G4 mixture (Fig. S8, ESI $\dagger) .{ }^{60}$ The peak positions of the $\mathrm{Li}^{+}-\mathrm{Li}^{+}$correlation in [Li(G3)][TFA] (Fig. 4(a)) have a good agreement with the $\mathrm{Li}^{+}$ $\mathrm{Li}^{+}$distances obtained from the crystal structure (see Table S5, ESI $\dagger$ ). It is feasible that $\mathrm{Li}^{+}-[\mathrm{TFA}]$ anion aggregation and the continuously ordered $\mathrm{Li}^{+}$structure observed in the crystal are maintained to some extent even in the liquid state.

\subsection{Relationship between dynamic ion correlations and $\mathrm{Li}^{+}$ transference number}

Here, we investigate the relationship between the dynamic ion correlations and the $\mathrm{Li}^{+}$transference number. $t_{\mathrm{Li}}^{\mathrm{PP}}$ can be defined using the Onsager transport coefficients as follows, ${ }^{55,56}$

$$
t_{\mathrm{Li}}^{\mathrm{PP}}=\frac{\beta^{2}-4 \alpha+4 \alpha^{2}}{4(1-\alpha)(\beta-1)}
$$

$$
\alpha=\frac{\sigma_{++}}{\sigma_{++}+\sigma_{--}}, \quad \beta=\frac{2 \sigma_{+-}}{\sigma_{++}+\sigma_{--}}
$$

If the ion motions are non-correlated $(\beta=0$ for cation-anion correlations), as postulated in ideal solutions, $t_{\mathrm{Li}}^{\mathrm{PP}}$ is equivalent to the parameters $\alpha$ and $t_{\mathrm{Li}}^{\mathrm{NMR}}$. In most cases of liquid electrolytes used in battery systems, however, ion correlations cannot be ignored. Thus, $t_{\mathrm{Li}}^{\mathrm{PP}}$ is significantly varied by the interplay between the cation-cation and cation-anion cross-correlations.

In Fig. $6, t_{\mathrm{Li}}^{\mathrm{PP}}$ is simulated versus $\beta$ for different $\alpha$ values. As predicted by eqn (7) (visualized in Fig. 6), the parameter $\alpha$ must be not less than $0.5(\alpha \geq 0.5)$ in order to achieve $t_{\mathrm{Li}}^{\mathrm{PP}}=1$. The parameter $\beta$ is well explained by the strength of the cationanion correlations represented by $\sigma_{+-}$. If the ion motions of the cation-anion are strongly anti-correlated, the value of $\beta$ approaches -1.0. However, if strong correlations exist between cations and anions in the electrolytes, the $\beta$ value approaches 1.0. Eqn (7) suggests that a $t_{\mathrm{Li}}^{\mathrm{PP}}$ value of unity is attainable in the range of $0 \leq$ $\beta \leq 1$. Consequently, the concentrated solution theory predicts the possibility of a single $\mathrm{Li}^{+}$ion conducting liquid electrolyte, and there are several approaches within $\alpha \geq 0.5$ and $0 \leq \beta \leq 1$.

The $\alpha$ and $\beta$ parameters for [Li(G3)][TFSA], [Li(G4)][ $\left.\mathrm{BF}_{4}\right]$, $[\mathrm{Li}(\mathrm{G} 3)][\mathrm{TfO}]$, and $[\mathrm{Li}(\mathrm{G} 3)][\mathrm{TFA}]$ are listed in Table 1. Furthermore, we illustrate the possible range of $t_{\mathrm{Li}}^{\mathrm{pP}}$ as a function of $\beta$ for different $\alpha$ values in Fig. 6, where the experimental values for [Li(glyme)]X are plotted. The Lewis basicity of the anions has an impact on both parameters $\alpha$ and $\beta$. According to our previous results, ${ }^{20}$ the low value of $\alpha(0.25)$ for [Li(G3)][TFSA] chiefly stems from the strong anti-correlation of cation-cation motions. However, the value of $\alpha$ is close to 0.5 for [Li(G3)][TFA] and higher than that of [Li(G3)][TFSA]. Almost the same values of $\sigma_{--}$and $\sigma_{++}$, which are attributed to the coupled ion motions in the form of ion clusters, would result in $\alpha \rightarrow 0.5$ for [Li(G3)][TFA]. The parameter $\beta$ predominantly depends on the Lewis basicity of the anion (eqn (8)). For [Li(G3)][TFSA], the anti-correlated ion motion of the cation-anion $\left(\sigma_{+_{-}}<0\right)$ results in a largely negative value of $\beta(-0.78)$. However, the $\beta$ value gradually increases as the ion motion of the cation-anion shifts

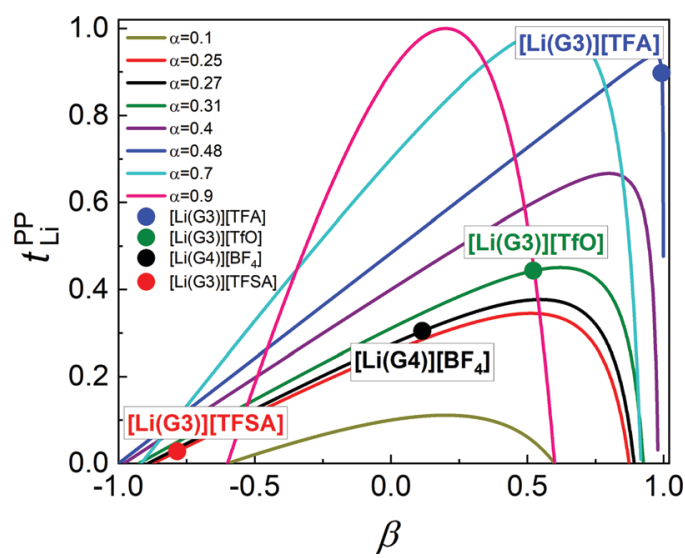

Fig. 6 Possible range of values for $t_{\mathrm{Li}}^{\mathrm{PP}}$ as a function of $\beta$ for different $\alpha$ values. The experimental data for [Li(G3)][TFSA], [Li(G4)][BF 4 , [Li(G3)][TfO], and [Li(G3)][TFA] are plotted in the figure. 
Table $1 \alpha$ and $\beta$ values for the equimolar glyme-Li salt mixtures

\begin{tabular}{llr}
\hline Sample & $\alpha$ & \multicolumn{1}{c}{$\beta$} \\
\hline$[\mathrm{Li}(\mathrm{G} 3)][\mathrm{TFSA}]^{20}$ & 0.25 & -0.78 \\
{$[\mathrm{Li}(\mathrm{G} 3)][\mathrm{TfO}]$} & 0.31 & 0.52 \\
{$[\mathrm{Li}(\mathrm{G} 3)][\mathrm{TFA}]$} & 0.48 & 0.99 \\
{$[\mathrm{Li}(\mathrm{G} 4)]\left[\mathrm{BF}_{4}\right]$} & 0.27 & 0.11
\end{tabular}

from anti-correlated $\left(\sigma_{+-}<0\right.$ for [Li(G3)][TFSA]) to nearly noncorrelated $\left(\sigma_{+-} \approx 0\right.$ for $\left.[\mathrm{Li}(\mathrm{G} 4)]\left[\mathrm{BF}_{4}\right]\right)$ to correlated $\left(\sigma_{+-}>0\right.$ for $[\mathrm{Li}(\mathrm{G} 3)][\mathrm{TfO}]$ and $[\mathrm{Li}(\mathrm{G} 3)][\mathrm{TFA}])$ with the increasing Lewis basicity of the anions. Therefore, the high $t_{\mathrm{Li}}^{\mathrm{PP}}$ of 0.90 is found to be a consequence of the correlated ion motions of the cationcation $(\alpha \approx 0.5)$ and cation-anion $(\beta \approx 1)$ in [Li(G3)][TFA].

For $[\mathrm{Li}(\mathrm{G} 3)][\mathrm{TFA}]$, in which the high $t_{\mathrm{Li}}^{\mathrm{PP}}$ is derived from strongly correlated ion motions $(\alpha \approx 0.5, \beta \approx 1)$, the ionic conductivity becomes very low $\left(0.096 \mathrm{mS} \mathrm{cm}^{-1}\right)$ because the large positive value of $\sigma_{+-}$negatively affects the ionic conductivity. Therefore, highly associating systems such as [Li(G3)][TFA] may not be adequate for simultaneously achieving high ionic conductivity and high $t_{\mathrm{Li}}^{\mathrm{PP}}$. In contrast, the previously studied SLbased molten Li salt solvates ([Li(SL) $][$ TFSA $]$ and $\left.\left[\mathrm{Li}(\mathrm{SL})_{3}\right][\mathrm{TFSA}]\right)$ showed a higher $\alpha$ value of $\sim 0.9$ and a $\beta$ parameter close to zero $\left(\beta=-0.18\right.$ in the case of $\left.\left[\mathrm{Li}(\mathrm{SL})_{3}\right][\mathrm{TFSA}]\right)$, and exhibited a relatively high $t_{\mathrm{Li}}^{\mathrm{PP}}$ value of $\sim 0.7$ and ionic conductivity of $1.0 \mathrm{mS} \mathrm{cm}{ }^{-1} .^{20}$ Therefore, liquid electrolyte systems with non-correlated cationanion ion motions $(\beta \approx 0)$ and strongly correlated cation-cation motions $(\alpha \approx 1)$ would be more appropriate for solving the tradeoff problem between $t_{\mathrm{Li}}^{\mathrm{PP}}$ and the ionic conductivity, as shown in Fig. 2.

\section{Conclusions}

The $t_{\mathrm{Li}}^{\mathrm{PP}}$ behavior of [Li(glyme) $] \mathrm{X}$ was investigated as a function of ionicity and was enhanced with as the ionicity decreased (i.e., as the Lewis basicity of the counter anions increased). However, a trade-off between the $t_{\mathrm{Li}}^{\mathrm{PP}}$ and ionic conductivity was observed, which is similar to that of solid polymer electrolyte systems. The highest $t_{\mathrm{Li}}^{\mathrm{PP}}$ of 0.93 was achieved for [Li(G4)][TFA], which had the lowest ionic conductivity of $0.083 \mathrm{mS} \mathrm{cm}^{-1}$, whereas the lowest $t_{\mathrm{Li}}^{\mathrm{PP}}$ value of 0.016 was found for [Li(G3)][FSA], with the highest ionic conductivity of $1.7 \mathrm{mS} \mathrm{cm}^{-1}$. To clarify this trade-off, we studied the dynamic ion correlations for each electrolyte based on Roling and Bedrov's concentrated solution theory. The largely positive value of $\sigma_{+-} / \sigma_{\text {ion }}$ was found to be the primary cause of the high $t_{\mathrm{Li}}^{\mathrm{PP}}$ of [Li(G3)][TFA], and conversely, led to its low ionic conductivity.

We further explored the liquid structures of [Li(G3)][TFSA] and $[\mathrm{Li}(\mathrm{G} 3)][\mathrm{TFA}]$ using a combination of HEXTS measurements and MD simulations. From the results of the $\mathrm{Li}^{+}-\mathrm{Li}^{+}$ and $\mathrm{Li}^{+}$-anion pair correlation functions, it can be stated that $\mathrm{Li}^{+}$ions preferentially interact with $\mathrm{G} 3$ and form $[\mathrm{Li}(\mathrm{G} 3)]^{+}$ complex cations in $[\mathrm{Li}(\mathrm{G} 3)][\mathrm{TFSA}]$. In contrast, $\mathrm{Li}^{+}$ions form an ordered structure through interaction with not only G3 molecules but also [TFA] anions in [Li(G3)][TFA]. These results strongly support the existence of ionic aggregates or ion clusters of $\left[\mathrm{Li}_{x}^{+}\left([\mathrm{TFA}]^{-}\right)_{y}\right]^{(x-y)}$ as well as neutral ion pairs of $\mathrm{Li}-[\mathrm{TFA}]$, as expected from the dynamic ion correlations.

We elucidated the $\mathrm{Li}^{+}$transference number as a function of the parameters $\alpha$ and $\beta$. [Li(glyme)]X with strongly associating anions, such as [Li(G3)][TFA], exhibited a high $t_{\mathrm{Li}}^{\mathrm{PP}}$ with low ionic conductivity due to strongly correlated ion motions $(\alpha \approx 0.5, \beta \approx 1)$. However, our analysis also suggested a possible approach to solving the trade-off using liquid electrolytes with non-correlated cation-anion ion motions $(\beta \approx 0)$ and strongly correlated cation-cation motions $(\alpha \approx 1)$. To develop an elaborate design principle for single-ion conducting liquid electrolytes with high ionic conductivity, future studies will focus on the achievement of $\alpha \approx 1$ and $\beta \approx 0$ values in low-viscosity liquid electrolyte systems.

\section{Conflicts of interest}

There are no conflicts to declare.

\section{Acknowledgements}

This study was supported in part by the Japan Society for the Promotion of Science (JSPS) KAKENHI (Grant No. $20 \mathrm{H} 02837$ to K. U., $20 \mathrm{H} 02823$ to K. F. and $18 \mathrm{H} 03926$ to K. D.) and by JST ALCA-SPRING (Grant Number JPMJAL1301), Japan.

\section{References}

1 M. Doyle, T. F. Fuller and J. Newman, Electrochim. Acta, 1994, 39, 2073-2081.

2 K. M. Diederichsen, E. J. McShane and B. D. McCloskey, ACS Energy Lett., 2017, 2, 2563-2575.

3 P. Barai, K. Higa and V. Srinivasan, J. Electrochem. Soc., 2018, 165, A2654-A2666.

4 H. Yoon, P. C. Howlett, A. S. Best, M. Forsyth and D. R. MacFarlane, J. Electrochem. Soc., 2013, 160, A1629-A1637.

5 Y. Yamada, K. Furukawa, K. Sodeyama, K. Kikuchi, M. Yaegashi, Y. Tateyama and A. Yamada, J. Am. Chem. Soc., 2014, 136, 5039-5046.

6 L. Suo, O. Borodin, T. Gao, M. Olguin, J. Ho, X. Fan, C. Luo, C. Wang and K. Xu, Science, 2015, 350, 938.

7 J. Alvarado, M. A. Schroeder, M. Zhang, O. Borodin, E. Gobrogge, M. Olguin, M. S. Ding, M. Gobet, S. Greenbaum, Y. S. Meng and K. Xu, Mater. Today, 2018, 21, 341-353.

8 M. Forsyth, H. Yoon, F. Chen, H. Zhu, D. R. MacFarlane, M. Armand and P. C. Howlett, J. Phys. Chem. C, 2016, 120, 4276-4286.

9 K. Dokko, D. Watanabe, Y. Ugata, M. L. Thomas, S. Tsuzuki, W. Shinoda, K. Hashimoto, K. Ueno, Y. Umebayashi and M. Watanabe, J. Phys. Chem. B, 2018, 122, 10736-10745.

10 X. Gao, F. Wu, A. Mariani and S. Passerini, ChemSusChem, 2019, 12, 4185-4193.

11 E. R. Logan and J. R. Dahn, Trends Chem., 2020, 2, 354-366. 12 L. O. Valóen and J. N. Reimers, J. Electrochem. Soc., 2005, 152, A882. 
13 S. Zugmann, M. Fleischmann, M. Amereller, R. M. Gschwind, H. D. Wiemhöfer and H. J. Gores, Electrochim. Acta, 2011, 56, 3926-3933.

14 D. B. Shah, K. R. Olson, A. Karny, S. J. Mecham, J. M. DeSimone and N. P. Balsara, J. Electrochem. Soc., 2017, 164, A3511-A3517.

15 J. Popovic, D. Höfler, J. P. Melchior, A. Münchinger, B. List and J. Maier, J. Phys. Chem. Lett., 2018, 9, 5116-5120.

16 P. Ravn Sørensen and T. Jacobsen, Electrochim. Acta, 1982, 27, 1671-1675.

17 M. Armand, Solid State Ionics, 1983, 9-10, 745-754.

18 J. Evans, C. A. Vincent and P. G. Bruce, Polymer, 1987, 28, 2324-2328.

19 Y. Tominaga, K. Yamazaki and V. Nanthana, J. Electrochem. Soc., 2015, 162, A3133-A3136.

20 K. Shigenobu, K. Dokko, M. Watanabe and K. Ueno, Phys. Chem. Chem. Phys., 2020, 22, 15214-15221.

21 K. Ueno, K. Yoshida, M. Tsuchiya, N. Tachikawa, K. Dokko and M. Watanabe, J. Phys. Chem. B, 2012, 116, 11323-11331.

22 D. Dong, F. Sälzer, B. Roling and D. Bedrov, Phys. Chem. Chem. Phys., 2018, 20, 29174-29183.

23 D. B. Shah, H. Q. Nguyen, L. S. Grundy, K. R. Olson, S. J. Mecham, J. M. DeSimone and N. P. Balsara, Phys. Chem. Chem. Phys., 2019, 21, 7857-7866.

24 H. Moon, R. Tatara, T. Mandai, K. Ueno, K. Yoshida, N. Tachikawa, T. Yasuda, K. Dokko and M. Watanabe, J. Phys. Chem. C, 2014, 118, 20246-20256.

25 S. Kohara, K. Suzuya, Y. Kashihara, N. Matsumoto, N. Umesaki and I. Sakai, Nucl. Instrum. Methods Phys. Res., Sect. A, 2001, 467-468, 1030-1033.

26 S. Sakai, National Laboratory for High Energy Physics, Tsukuba, Japan, 1990.

27 D. T. Cromer, J. Chem. Phys., 1969, 50, 4857-4859.

28 J. H. Hubbell, W. J. Veigele, E. A. Briggs, R. T. Brown, D. T. Cromer and R. J. Howerton, J. Phys. Chem. Ref. Data, 1975, 4, 471-538.

29 S. Nosé, Mol. Phys., 1984, 52, 255-268.

30 W. G. Hoover, Phys. Rev. A: At., Mol., Opt. Phys., 1985, 31, 1695-1697.

31 J. N. Canongia Lopes and A. A. H. Pádua, J. Phys. Chem. B, 2004, 108, 16893-16898.

32 W. D. Cornell, P. Cieplak, C. I. Bayly, I. R. Gould, K. M. Merz, D. M. Ferguson, D. C. Spellmeyer, T. Fox, J. W. Caldwell and P. A. Kollman, J. Am. Chem. Soc., 1995, 117, 5179-5197.

33 W. L. Jorgensen, D. S. Maxwell and J. Tirado-Rives, J. Am. Chem. Soc., 1996, 118, 11225-11236.

34 E. K. Watkins and W. L. Jorgensen, J. Phys. Chem. A, 2001, 105, 4118-4125.

35 S. Saito, H. Watanabe, K. Ueno, T. Mandai, S. Seki, S. Tsuzuki, Y. Kameda, K. Dokko, M. Watanabe and Y. Umebayashi, J. Phys. Chem. B, 2016, 120, 3378-3387.

36 J.-C. Soetens, C. Millot and B. Maigret, J. Phys. Chem. A, 1998, 102, 1055-1061.
37 C. M. Breneman and K. B. Wiberg, J. Comput. Chem., 1990, 11, 361-373.

38 Y. Kamiyama, M. Shibata, R. Kanzaki and K. Fujii, Phys. Chem. Chem. Phys., 2020, 22, 5561-5567.

39 K. Hayamizu, Y. Aihara, S. Arai and C. G. Martinez, J. Phys. Chem. B, 1999, 103, 519-524.

40 Y. Ugata, R. Tatara, K. Ueno, K. Dokko and M. Watanabe, J. Chem. Phys., 2020, 152, 104502.

41 P. G. Bruce, J. Evans and C. A. Vincent, Solid State Ionics, 1988, 28-30, 918-922.

42 M. Watanabe, S. Nagano, K. Sanui and N. Ogata, Solid State Ionics, 1988, 28-30, 911-917.

43 M. D. Galluzzo, J. A. Maslyn, D. B. Shah and N. P. Balsara, J. Chem. Phys., 2019, 151, 020901.

44 D. R. MacFarlane, M. Forsyth, E. I. Izgorodina, A. P. Abbott, G. Annat and K. Fraser, Phys. Chem. Chem. Phys., 2009, 11, 4962-4967.

45 K. R. Harris, J. Phys. Chem. B, 2010, 114, 9572-9577.

46 K. Ueno, H. Tokuda and M. Watanabe, Phys. Chem. Chem. Phys., 2010, 12, 1649-1658.

47 H. K. Kashyap, H. V. R. Annapureddy, F. O. Raineri and C. J. Margulis, J. Phys. Chem. B, 2011, 115, 13212-13221.

48 C. Austen Angell, Y. Ansari and Z. Zhao, Faraday Discuss., 2012, 154, 9-27.

49 W. A. Henderson, J. Phys. Chem. B, 2006, 110, 13177-13183.

50 W. Shinoda, Y. Hatanaka, M. Hirakawa, S. Okazaki, S. Tsuzuki, K. Ueno and M. Watanabe, J. Chem. Phys, 2018, 148, 193809.

51 L. A. Woolf, J. Phys. Chem., 1978, 82, 959-962.

52 L. A. Woolf and K. R. Harris, J. Chem. Soc., Faraday Trans. 1, 1978, 74, 933-947.

53 D. M. Pesko, K. Timachova, R. Bhattacharya, M. C. Smith, I. Villaluenga, J. Newman and N. P. Balsara, J. Electrochem. Soc., 2017, 164, E3569-E3575.

54 I. Villaluenga, D. M. Pesko, K. Timachova, Z. Feng, J. Newman, V. Srinivasan and N. P. Balsara, J. Electrochem. Soc., 2018, 165, A2766-A2773.

55 F. Wohde, M. Balabajew and B. Roling, J. Electrochem. Soc., 2016, 163, A714-A721.

56 N. M. Vargas-Barbosa and B. Roling, ChemElectroChem, 2020, 7, 367-385.

57 K. Fujii, M. Matsugami, K. Ueno, K. Ohara, M. Sogawa, T. Utsunomiya and M. Morita, J. Phys. Chem. C, 2017, 121, 22720-22726.

58 S. Tsuzuki, W. Shinoda, M. Matsugami, Y. Umebayashi, K. Ueno, T. Mandai, S. Seki, K. Dokko and M. Watanabe, Phys. Chem. Chem. Phys., 2015, 17, 126-129.

59 K. Ueno, R. Tatara, S. Tsuzuki, S. Saito, H. Doi, K. Yoshida, T. Mandai, M. Matsugami, Y. Umebayashi, K. Dokko and M. Watanabe, Phys. Chem. Chem. Phys., 2015, 17, 8248-8257.

60 W. A. Henderson, N. R. Brooks and V. G. Young, Chem. Mater., 2003, 15, 4685-4690. 